\title{
Unlicensed Assistive Personnel
}

National Cancer Institute

\section{Source}

National Cancer Institute. Unlicensed Assistive Personnel. NCI Thesaurus. Code C20861.

Personnel trained to assist with the direct care of patients in all health settings and in the home. Unlicensed Assistive Personnel work under the direct supervision of RNs to extend the abilities of the nurse to provide for patients' activities of daily living. 